\title{
Current Attitudes of Anesthesiologists towards Medically Futile Care
}

\author{
Angela Saettele, Joseph Kras \\ Department of Anesthesiology, Washington University, Saint Louis, USA. \\ Email: saettelea@anest.wustl.edu \\ Received March $30^{\text {th }}, 2013$; revised April 30 $0^{\text {th }}, 2012$; accepted May $15^{\text {th }}, 2013$ \\ Copyright (C) 2013 Angela Saettele, Joseph Kras. This is an open access article distributed under the Creative Commons Attribution \\ License, which permits unrestricted use, distribution, and reproduction in any medium, provided the original work is properly cited.
}

\begin{abstract}
Purpose: To explore anesthesiologists' perceptions of the reasons underlying why physicians continue to provide care that they consider futile. Methods: A qualitative study was conducted utilizing a grounded theory approach. Four separate focus groups ( 2 resident physician groups and 2 attending physician groups) were conducted over a three week span. An interview guide was used consisting of a proposed definition of futility and five open-ended questions. Responses to the five open-ended questions were used to guide follow up questions. Transcribed audio recordings were then analyzed. Results: With data reduction, we were able to separate responses into definitions of futility, stories of cases where futile care was provided, and opinions as to the underlying causes of continuing to provide futile care. A variety of opinions was obtained, suggesting the possibility that different groups (surgeons, anesthesiologists, family members) view questions of futility differently. Conclusions: Complete agreement on a definition of futility does not exist. Even when some agreement exists, there is great difficulty in predicting outcomes in individual cases. Future quantitative studies may provide more evidence of trends in underlying reasons for providing futile care. Focused education efforts may then lead to more agreement between all involved.
\end{abstract}

Keywords: Medical Futility; End of Life Care; Quality of Life; Withdrawal of Care

\section{Introduction}

Advances in technology have allowed the medical profession to keep those with terminal illnesses alive for longer periods of time without curing the underlying pathology. Even though life may be prolonged, the quality of that prolonged life is not necessarily preserved. One general definition of medical futility is that of a specific intervention applied to a specific patient that is unlikely to provide a specific benefit. Although most people agree that futile care should not be provided, there can be a wide range of opinion as to what constitutes futile care in any given clinical situation. There are multiple downsides of providing futile care. Any medical intervention has both risks and benefits involved. In the case of futile care, there is no significant benefit that can reasonably be obtained, so the risks involved are likely to outweigh the benefits. These risks can range from relatively minor such as pain from repeated blood draws and intravenous lines to death from a massive pulmonary embolism that developed in the perioperative period due to immobility [1]. Providing futile care may go against the prior wishes of the patient in cases where family members continue to insist that "Everything be done". Furthermore these advanced technologies have high costs in relation to manpower and resource utilization in addition to the financial costs.

In order to discuss medically futile care, a common concept of what constitutes medically futile care needs to be established. The phrase "futile care" in itself is meaningless without something to which it relates. This is where much of the debate about the definition of medical futility stems. As Truog et al. have pointed out, the problem with defining futility is that it involves differing individual values, as well as the fact that almost nothing is ever $100 \%$ ineffective [2]. Despite these difficulties, it can be useful to further define the concept of futility. Five main categories of futility have been previously described. These are physiological, quantitative, qualitative, imminent demise, and lethal condition futility [3].

Physiological futility describes care in which specific physiologic goals are unable to be obtained $[2,4]$. An example would be cardiopulmonary resuscitation (CPR) in which the physiologic goal is the return of a sponta- 
neously beating heart. Even if correctly performed CPR provides perfusion to different organs, it may still be considered futile if there is no hope of a spontaneous heartbeat. Almost all interventions will have some sort of physiological effect, but one must decide what physiological effect you are expecting from the intervention [5]. Having an effect is different from providing benefit to the patient. Most of our current medical interventions do work in the immediate time period. However, often the questions remain of whether there is long term physiological benefit, as well as overall benefit in respect to the patient's goals. The American Society of Anesthesiologists (ASA) Syllabus on Ethics uses a primarily physiologic definition of utility, defining futile care as a specific medical intervention applied to a specific patient at a particular time that fails to achieve the goals of medical therapy [6].

The notion of quantitative futility was introduced by Schneiderman and colleagues in 1990, in an attempt to facilitate objective discussions of futility [7]. The authors suggested that if the last 100 cases had been useless, the treatment should be considered futile. This definition begs the question of whether 0 in 100 is the proper cutoff, arbitrary as it seems. The qualitative question of what constitutes "useless" in this definition is also open to interpretation.

Qualitative futility describes whether an intervention is able to achieve a reasonable quality of life for a person. The downside is that using qualitative futility creates the need to additionally define quality of life. Questions of what constitutes a reasonable quality of life and who gets to define it (patient, surrogate, or care team) are difficult if not impossible to settle.

The last two categories are similar, yet with distinct but subtle differences. When a patient is going to die in the near future whether an intervention is completed or not, it is referred to as imminent demise futility. On the other hand, lethal condition futility describes a patient who has a condition that will lead to the patient's death in the near future, despite treating other conditions that the patient has. An example would be a patient with metastatic cancer who also has symptomatic aortic stenosis. Replacing the patient's aortic valve would improve the patient's survival from the cardiac standpoint. However, the patient still has metastatic cancer that will cause death. Replacing the patient's aortic valve will not change that fact, and thus the surgery could be considered futile in that respect.

In today's economic climate, there is increasing pressure to decrease the cost of healthcare and increase productivity. Even though resources at times seem unlimited, the healthcare system is increasingly being reminded that healthcare dollars are a finite resource. Futile care for one person today may mean that another individual in the future may not be able to reap those same benefits. It is also important when talking about increased healthcare costs to distinguish between care that it truly futile and that which is not futile, but merely inadvisable due to a very high cost to benefit ratio.

Even with all of the potential negative aspects of futile care, anecdotal evidence suggests that this care continues to be provided. Many articles describe medical futility and the role it plays in end of life care, but very few attempt to describe why medical futility continues to occur even at the risk of potential pitfalls. The majority of the articles are based on expert opinions and theories of ethics, rather than on actual clinical practices. This project will characterize the current attitudes and clinical practices regarding futile care by one segment of United States physicians who frequently care for critically ill patients.

\section{Methods}

A grounded theory qualitative approach was chosen for this study [8]. Grounded theory was first described by Glaser and Strauss in 1967, as a method of building theoretical constructs out of qualitative data [9]. All attendings, fellows, and residents of the Departments of Anesthesiology and Surgery at our institution were invited to participate. Recruitment was completed through announcements at various departmental lectures along with emails detailing the study. 16 physicians voluntarily attended one of four focus groups during which semi structured interviews were performed. On arrival to the interview session, each participant filled out a demographic form and informed consent was obtained. The demographic questionnaire included information about age, gender, years since medical school, department (anesthesiology or surgery), primary practice setting (operating room or intensive care unit), religion, and attendance of religious services.

For consistency, all interviews were conducted by both authors. An interview guide was used consisting of a proposed definition of futility and five open-ended questions (Table 1). Responses to the five open-ended ques-

Table 1. Interview field guide.

Medical futility is often defined as an intervention that is unlikely to produce any significant benefit towards the patient. For our purposes, medical intervention can include any procedure, surgery, administration of intravenous or oral medications, or radiographic or laboratory testing that is ordered or performed by a physician.

1) Do you agree with that definition of futility?

2) Within the last 12 months, have you been a witness to a patient receiving futile care?

3) Have you had someone in your care who you thought was receiving futile care?

4) Why was that care provided?

5) Has either witnessing or taking part in a patient's futile care changed the way you practice medicine? 
tions were used to guide follow up questions. Interviewers facilitated discussion without inserting any of their personal views into the discussions. Each session was audio recorded and transcribed afterwards. Data reducetion was completed by sorting the data into the three major categories of definition, stories, and underlying causes. These categories were then further reduced into subcategories. Coding was performed manually. Each category and subcategory was analyzed along with the participants' demographic information to determine if any patterns or recurrent themes could be identified. This project received Institutional Review Board approval.

\section{Results}

The makeup of the participants were $63 \%$ male. $69 \%$ were in the 20 - 40 age range, and $31 \%$ were in the 41 60 age range. $63 \%$ were within 5 years of medical school, $19 \%$ within 11 - 20 years, and 19\% within $21-30$ years (Table 2). All of the participants were from the Department of Anesthesiology. No one from the Department of Surgery volunteered for the project. $56 \%$ of participants reported attending religious services weekly, 25\% attended monthly, and 19\% never.

Initially participants were asked if they agreed with a definition of futility derived from the ASA Syllabus on Ethics. The majority of participants agreed with this primarily physiological definition, but many participants went on to expand on what they meant by futility.
Participant 16 (M, 21 - 30, non-religious) [gender, age group, religion] added economics to the definition, saying "I think that I would add the idea that spending money that is not worth spending is also part of the concept ...". Participant 11 (M, 21 - 30, religious) expanded the concept of physiologic benefit to a larger benefit to the family unit relating how a left ventricular assist device put into his mother after a myocardial infarction extended her life for about 14 hours. "So what benefit did it have for her? Almost none. For me, it was immeasurable. Because I got to see her while she was still alive and conscious."

Quality of life entered into several participants' definition. Participant $5(\mathrm{M},<5$, religious) opined “... a certain intervention may extend or prolong (life) or benefit the patient to some degree, (but) there may be other providers who don't agree that it's prolonging a life necessarily or improving the outcomes. (I)t may be just extending sub-optimal quality of life care." Participant 9 (M, <5, Blank) said, “”. restoring or maintaining life is one thing, but having a good quality of life is what I think would really weigh in consideration. Not just keeping people alive, but making sure that they are able to enjoy the things they enjoy, and participate in their family the way they have (in the past)." Some narrowed quality of life to "quality of life years" considerations. Participant 4 (F, <5, spiritual) added "I think it matters not just persons saved, but time or qualities saved. So at a children's hospi-

Table 2. Participant demographics.

\begin{tabular}{|c|c|c|c|c|c|c|c|}
\hline & Age & Gender & $\begin{array}{l}\text { Years since } \\
\text { graduation }\end{array}$ & Clinical Role & Practice Setting & Religious & Attends Services \\
\hline 1 & $<41$ & Female & $<5$ & Resident & Operating room & Religious & Monthly \\
\hline 2 & $<41$ & Male & $<5$ & Resident & Operating room & Religious & Weekly \\
\hline 3 & $<41$ & Male & $<5$ & Resident & Operating room & Blank & Weekly \\
\hline 4 & $<41$ & Female & $<5$ & Resident & Operating room & Spiritual & Monthly \\
\hline 5 & $<41$ & Male & $<5$ & Resident & Operating room & Religious & Weekly \\
\hline 6 & $41-60$ & Male & $11-20$ & Resident & Operating room & Religious & Weekly \\
\hline 7 & $<41$ & Female & $<5$ & Resident & Operating room & Blank & Weekly \\
\hline 8 & $<41$ & Male & $<5$ & Resident & Operating room & Blank & Monthly \\
\hline 9 & $<41$ & Male & $<5$ & Resident & Operating room & Blank & Weekly \\
\hline 10 & $<41$ & Male & $<5$ & Resident & Operating room & Religious & Weekly \\
\hline 11 & $41-60$ & Male & $21-30$ & Faculty & Operating room & Religious & Weekly \\
\hline 12 & $41-60$ & Female & $21-30$ & Faculty & Operating room & Neither & Never \\
\hline 13 & $<41$ & Male & $11-20$ & Faculty & Operating room & Religious & Weekly \\
\hline 14 & $<41$ & Female & $<5$ & Faculty & Intensive care unit & Spiritual & Monthly \\
\hline 15 & $41-60$ & Female & $11-20$ & Faculty & Operating room & Spiritual & Never \\
\hline 16 & $41-60$ & Male & $21-30$ & Faculty & Operating room & Neither & Never \\
\hline
\end{tabular}


tal $\cdots$ if you save them for a whole lifetime $\cdots$ versus we might have a save in the (adult) ICU (intensive care unit) which ends up a year later dying ..." Participant 16 (M, 21 - 30, non-religious) related a case where " $\cdots$ a couple of weeks ago, I was in the cardiac cath (eterization) lab and we had a 90 year old patient with leukemia who underwent placement of a defibrillator. And to me that sounded quite futile." Participant 13 (M, 11 - 16, religious) said, "I think that your best guess as to the benefits is obviously a criteria, and that age is one thing that (is a factor)."

After discussing the definition of futility, conversations turned toward discussion of why futile care continues to take place. During initial data reduction, we were able to identify four major underlying sources of reasons for medically futile care: patient/family, surgeon, anesthesiologist/ICU team, and medico-legal (Tables 3-9).

Patients and their families were noted as an underlying cause for several different reasons. One reason that was discussed extensively was that patients and families rarely have full understanding of their medical situation. Participant 4 (F, $<5$, spiritual) said, "The other thing is that our ICU's are so complicated ' And I think it is really not fair to make the family make calls $\cdots$ The family has no idea of what the complexities are, and I think at some point, if you've gotten into that ground that I don't think it's fair to ask them anymore what they think.

Table 3. Underlying causes discussed.

\begin{tabular}{l}
\hline - Family/Patient \\
- Not enough knowledge to fully understand situation \\
- Don't want to be the one to "pull the plug" \\
- Invested/Been through a lot already, what's one more \\
intevention \\
- Patient wanted everything/Advanced directive \\
- Manipulated into agreeing \\
- Cites religious reasons \\
- Surgeon \\
- Invested in patient \\
- "I can fix it" mentality \\
- Doesn't think about the risks involved \\
- Academic center, need to try and practice new techniques \\
- Anesthesia can't refuse/it's a referral service \\
- Remembers that “miracle pt" \\
- Anesthesiologist/ICU team \\
- Poor ability to prognosticate \\
- Remembers that “miracle pt" \\
- Doesn't want a death on their name, wants someone else to \\
- make decision \\
- Not worth fighting with the surgeons/complacency \\
- Involved in care for only one day/don't know entire story/not \\
- I'm just a resident/I'm just doing what I'm told \\
-
\end{tabular}

Table 4. Reasons for futile care, by participant.

\begin{tabular}{cccccc}
\hline & $\begin{array}{c}\text { Anesthesia/ } \\
\text { Intensive Care } \\
\text { Unit }\end{array}$ & Surgeon & $\begin{array}{c}\text { Family/ } \\
\text { Patient }\end{array}$ & Medico-legal & $\begin{array}{c}\text { Don't } \\
\text { Know }\end{array}$ \\
\hline 1 & $\mathrm{X}$ & $\mathrm{X}$ & $\mathrm{X}$ & $\mathrm{X}$ & $\mathrm{X}$ \\
2 & $\mathrm{X}$ & $\mathrm{X}$ & $\mathrm{X}$ & & $\mathrm{X}$ \\
3 & $\mathrm{X}$ & & $\mathrm{X}$ & & \\
4 & $\mathrm{X}$ & $\mathrm{X}$ & $\mathrm{X}$ & & \\
5 & $\mathrm{X}$ & $\mathrm{X}$ & $\mathrm{X}$ & & \\
6 & $\mathrm{X}$ & & & & \\
7 & $\mathrm{X}$ & $\mathrm{X}$ & & $\mathrm{X}$ & $\mathrm{X}$ \\
8 & $\mathrm{X}$ & $\mathrm{X}$ & & & $\mathrm{X}$ \\
9 & & $\mathrm{X}$ & & & \\
10 & & & & & \\
11 & $\mathrm{X}$ & & $\mathrm{X}$ & $\mathrm{X}$ & \\
12 & $\mathrm{X}$ & & $\mathrm{X}$ & $\mathrm{X}$ & \\
13 & $\mathrm{X}$ & $\mathrm{X}$ & $\mathrm{X}$ & & $\mathrm{X}$ \\
14 & $\mathrm{X}$ & $\mathrm{X}$ & $\mathrm{X}$ & & \\
15 & $\mathrm{X}$ & $\mathrm{X}$ & $\mathrm{X}$ & $\mathrm{X}$ & $\mathrm{X}$ \\
16 & $\mathrm{X}$ & $\mathrm{X}$ & $\mathrm{X}$ & & $\mathrm{X}$ \\
\hline
\end{tabular}

Table 5. Reasons given, by age of participant.

\begin{tabular}{cccccc}
\hline & $\begin{array}{c}\text { Anesthesia/ } \\
\text { Intensive Care } \\
\text { Unit }\end{array}$ & Surgeon & $\begin{array}{c}\text { Family/ } \\
\text { Patient }\end{array}$ & Medico-legal & $\begin{array}{c}\text { Don’t } \\
\text { Know }\end{array}$ \\
$<41$ & $9 / 11$ & $9 / 11$ & $7 / 11$ & $2 / 11$ & $6 / 11$ \\
$40-60$ & $5 / 5$ & $2 / 5$ & $4 / 5$ & $3 / 5$ & $2 / 5$ \\
\hline
\end{tabular}

Table 6. Reasons given, by gender of participant.

\begin{tabular}{cccccc}
\hline \multicolumn{3}{c}{$\begin{array}{c}\text { Anesthesia/ } \\
\text { Intensive Care Surgeon } \\
\text { Unit }\end{array}$} & $\begin{array}{c}\text { Family/ } \\
\text { Patient }\end{array}$ & Medico-legal & $\begin{array}{c}\text { Don't } \\
\text { Know }\end{array}$ \\
\hline Male & $8 / 10$ & $6 / 10$ & $6 / 10$ & $1 / 10$ & $4 / 10$ \\
Female & $6 / 6$ & $5 / 6$ & $5 / 6$ & $4 / 6$ & $4 / 6$ \\
\hline
\end{tabular}

Table 7. Reasons given, by years since graduation.

\begin{tabular}{cccccc}
\hline & $\begin{array}{c}\text { Anesthesia/ } \\
\text { Intensive } \\
\text { Care Unit }\end{array}$ & Surgeon & $\begin{array}{c}\text { Family/ } \\
\text { Patient }\end{array}$ & Medico-legal & $\begin{array}{c}\text { Don't } \\
\text { Know }\end{array}$ \\
\hline$<5$ & $8 / 10$ & $8 / 10$ & $6 / 10$ & $2 / 10$ & $5 / 10$ \\
$11-20$ & $3 / 3$ & $2 / 3$ & $1 / 3$ & $1 / 3$ & $2 / 3$ \\
$21-30$ & $3 / 3$ & $1 / 3$ & $3 / 3$ & $2 / 3$ & $1 / 3$ \\
\hline
\end{tabular}

Because how can they possibly understand the medical situation. Participant 12 (F, 21 - 30, non-religious) added, "I don't think patients always have a clear picture of their options. And I think it's hard to present those options in a clear fashion, particularly when you're dealing with high emotional states." 
Table 8. Reasons given, by religiosity.

\begin{tabular}{|c|c|c|c|c|c|}
\hline & $\begin{array}{l}\text { Anesthesia/ } \\
\text { Intensive } \\
\text { Care Unit }\end{array}$ & Surgeon & $\begin{array}{c}\text { Family/ } \\
\text { Patient }\end{array}$ & Medico-legal & $\begin{array}{l}\text { Don't } \\
\text { Know }\end{array}$ \\
\hline Religious & $6 / 7$ & $4 / 7$ & $5 / 7$ & $2 / 7$ & $4 / 7$ \\
\hline Spiritual & $3 / 3$ & $3 / 3$ & $3 / 3$ & $1 / 3$ & $1 / 3$ \\
\hline Neither & $2 / 2$ & $1 / 2$ & $2 / 2$ & $1 / 2$ & $1 / 2$ \\
\hline Blank & $3 / 4$ & $3 / 4$ & $1 / 4$ & $1 / 4$ & $2 / 4$ \\
\hline
\end{tabular}

Table 9. Reasons given, by religious service attendance.

\begin{tabular}{cccccc}
\hline & $\begin{array}{c}\text { Anesthesia/ } \\
\text { Intensive } \\
\text { Care Unit }\end{array}$ & Surgeon & $\begin{array}{c}\text { Family/ } \\
\text { Patient }\end{array}$ & Medico-legal & $\begin{array}{c}\text { Don't } \\
\text { Know }\end{array}$ \\
\hline Weekly & $7 / 9$ & $5 / 9$ & $5 / 9$ & $2 / 9$ & $3 / 9$ \\
Monthly & $4 / 4$ & $4 / 4$ & $3 / 4$ & $1 / 4$ & $3 / 4$ \\
Never & $3 / 3$ & $2 / 4$ & $3 / 3$ & $2 / 3$ & $2 / 3$ \\
\hline
\end{tabular}

Patients and (more commonly) their families were often cited as wanting to continue at all costs, not wanting to let go, and not wanting to be the ones to say to stop. Typical comments included Participant 6 (M, 11 - 20, religious) relaying “ $\cdots$ if the patient's your family member, no matter how low the (chance of success), you still want the treatment." There were also several variants of Participant 12's (F, 21 - 30, non-religious) comment that "... my experience with families in these situations is that the angst comes not over the fact that somebody is sick and dying, but the angst comes over the fact that they don't want to be responsible for the death." Participant 15 (F, $11-20$, spiritual) related how family issues spill over into ICU decisions, "Sometimes there's family involved, and family that need to have the impression that everything has been done, especially if there have been disagreements in the family between the patient and some of the family members $\cdots$ (Family members) start all these emotionally gripping fights on the decisions that have to be made for the patient." Finally, some participants noted that families would sometimes play "the religion card" to justify not discontinuing aggressive care.

The majority of participants cited surgeons as one of the underlying causes of the provision of futile care. Many comments cited the fact that surgeons are, by the nature of their practice, more invested in the patient. A typical comment came from Participant $5(\mathrm{M},<5$, religious), “... I think they have a vested interest in that patient, you know, walking out the door. If that patient came in under their care, that's their job, to fix them and walk them back out the door." Others cited their impresssion that patients had been told the best-case scenario, without a realistic estimation of the potential downsides.
Participant 14 (F, $<5$, spiritual) said, "I've heard surgeons tell me after they fix a Type A dissection on an 87 year old 'Well, she wanted to have surgery. She agreed to it.' She was do not resuscitate when she rolled into the emergency room and (the surgeon) changed her because (he) said you may walk out of here". Participant $5(\mathrm{M},<5$, religious) noted the role of surgeons in pushing the envelope of what was possible. "And if you don't take cases that others may view as futile and make an effort, we're never going to learn how to do X, Y, or Z."

Anesthesiologists and ICU intensivists were also cited as contributing to futile care. It seemed that the most frequently cited reason for this is an individual's poor ability to prognosticate. Participant $8(\mathrm{M},<5$, blank) remarked, "But I have been proven wrong though, where I thought a patient was going to do horribly and they had a hard post-operative CTICU (cardiothoracic ICU) stay, and $\cdots$ after a couple of weeks, (they) did get better and got out of the hospital and looked good." Reluctance on the part of physicians to "rock the boat" was also cited. Participant $2(\mathrm{M},<5$, religious) related his opinion that "In private practice if the surgical group does not like the anesthesiology group enough, they will tell the hospital and the hospital, well, you know, if you get enough complaints, they will find another anesthesiology group to staff the operating rooms." The argument that the surgeons knew the patient better was also offered. Participant 16 (M, 21 - 30, non-religious) remarked, "(The surgeons) $\cdots$ have the possibility (of seeing) the patient several times before surgery. It's very difficult for anesthesiologists in the short time before surgery when we meet the patient for the first time in the holding area to do anything reasonable about (their decision to proceed with questionable surgery)." Differing outlooks of different ICU attending staff was also noted to affect how far care was pushed. Participant 2 (M, $<5$, religious) said, “... it depends week to week who the ICU attending is. If you happen to get a very aggressive attending who wants to provide all care then that patient will get care and $\cdots$ the family discussion may not happen."

Medicolegal concerns were not mentioned that often during discussions. Participant 1 (F, $<5$, religious) said, "I think the problem is that we live in a medicolegal society, not just a medical society." Participant 15 (F, 11 20, spiritual) said, "I think this is a big part of it. Like physicians are afraid of taking a strong position for which they may be held liable or responsible later."

\section{Discussion}

Although there was no disagreement with the original physiological definition of futility, there was a fair amount of expansion of the definition. We believe this reflects the divergent views of futility held by those both 
within the general medical community, as well as the general public. Multiple authors have documented the difficulty in coming to agreement on a single definition of futility in regards to medical care $[2,4,5]$. It was also mentioned that some interventions that were clearly futile from a physiological standpoint were sometimes held by family to be of inestimable value when they allowed family members to get to the bedside of a still living patient.

Once we accept that a spectrum of definitions exist, why do we still provide it? Why do doctors continue to provide care that they feel provides no discernible benefit? Besides possessing a different definition, two other underlying reasons for the provision of futile care were supported by our interviews. One was the possession of what Joan Cassell calls different "moral economies" and the other was what we term "psycho-emotional investment".

The first theme that emerged was how different definitions can influence what care gets provided. Examples were given where anesthesiologists were taking a patient to the operating room for surgery when the overall condition of the patient was very poor. Either the patient themselves or a family member felt the surgery should be performed, even if the perceived overall benefit by physicians was minimal. A closely related variant were several mentions of uncertainty regarding whether a particular intervention would be successful in achieving its goals or not. As both Luce and Frick et al. have pointed out, while prognostic scoring systems used by intensiveists are good at stratifying patients according to severity of illness, they have limited positive and negative predictive value $[10,11]$. In other words, in the end each patient is an individual, and there will always be patients that "make it" who most people think won't. And of course, if uncertainty exists whether an intervention will work, most patients and their families will err on the side of believing that their case will be the one where the intervention will be successful.

Joan Cassell has referred to the different systems of ethics she observed amongst intensivists and surgeons as differing "moral economies" [12]. Intensivists are said to have an ethic of scarce resources, while surgeons are said to possess a covenantal ethic which is also referred to as surgical buy-in by Schwarze et al. [13]. Many of our participants' responses were supportive of Cassell's observations. Anesthesiologists generally were seen to share the intensivists' ethic of scarce resources. Several participants related stories in which surgeons either took someone to the operating room that they didn't think was indicated or refused to consider withdrawal of care on patients who had worsening multisystem organ failure over several weeks in the ICU. These different moral economies were described by Cassell as representing not just a different outlook, but a different core set of values. Differences in core values would certainly explain why discussions of plans for individual patients can become quite heated.

If disagreements towards the amount of aggressiveness in care results from differences in core values, then one would expect those viewpoints to be stable over time. Core values should apply equally from one patient to the next. We saw some indication that there are instances in which an individual's core values seemed to change. One participant illustrated this with his comment. He stated that when the patient is a family member, no matter how low the chance of success of treatment, it is generally wanted. This comment is consistent with what has been described by Dresser in her compilations of stories of medical ethicists who have personal experience with cancer in either themselves or a close family member [14]. In her book, Dresser details how all of the theories of bioethics and what was generally recommended to patients by ethicists were severely challenged and often ignored when the serious disease was personal.

One way of explaining why attitudes are different on which interventions should be provided might be to consider decision making as a function of what we term psycho-emotional influence. Psycho-emotional influence (PEI) would represent all of the psychological and emotional factors within oneself which influence how the "facts" of the case are approached. How we react to external stressors has been shown to result both in internal changes [15] as well as external behavior modifications [16]. We believe that PEI encompasses the work of Cassell, while explaining why people sometimes deviate from their seeming core values.

Patients and their families could be predicted to be the most emotionally invested in the patient's best outcome. They bring a lifetime's worth of experiences and emotions with them, and are further stressed by acute factors such as time pressure, vulnerability, confusion, and uncertainty. Because they have "the most to lose" when a patient dies, we expect that patients and their families will be most resistant to discontinuation of potentially life-sustaining interventions. Even though such interventions might hold a very small chance of bettering the patient's outcome, the influence of psychological and emotional factors on families and patients might be such that they overwhelm what others consider to be well established facts. PEI may encompass both personal factors as well as the influence of external factors such as religious teachings. Many seek comfort and support from their religious beliefs during times of crisis. Depending on religious denomination, traditions of believing in miraculous healing may have deep psychological roots that influence decision making during critical illness.

Cassell not only related how surgeons and intensivists 
appeared to operate under different moral economies, but also documented in her observations how surgeons acting as intensivists for other surgeon's patients acted much more like intensivists rather than surgeons. Rather than explaining this as a change or compromise of their internal moral economy, we see this as evidence of how their different roles in the case influence them from a psychoemotional standpoint. The surgeon's role with its covenantal ethic, influences the surgeon's actions towards patient's on which (s)he operates. If (s)he is treating a patient on which (s)he did not operate, the influence of that covenant is not present, and the surgeon intensivist can then be expected to act more like an anesthesiologist intensivist who puts the individual patient into the context of the entire ICU population.

\section{Conclusion}

The topic of medical futility is complex and without easy answers. Not only is there no consensus as to the definition of medical futility, the underlying causes of futile care are multi-factorial. We have identified several factors perceived to be problems by our participants, including disagreement on the definition of futility, differing core values, and the influence that psychological and emotional factors have on decision making. The design of this study does not allow for the quantification of which of these issues is perceived as contributing the most to the delivery of this type of care, but it does allow us to explore the breadth of the issues involved. The end goal to this line of research would be to determine if there are areas in which education and improved communication could decrease the amount of futile care being delivered. Broad programs directed to mass numbers of providers are unlikely to be successful and less likely to be well received by clinicians while more targeted programs directed at the most common situations are more likely to be successful at achieving that goal. This study does not attempt to quantify the different underlying causes and determine which is the most prevalent. However, this study may pave the way to discussion and further quantitative research to determine where education and intervention might be the most useful.

\section{REFERENCES}

[1] M. S. Niederman and J. T. Berger, "The Delivery of Futile Care Is Harmful to Other Patients," Critical Care Medicine, Vol. 38, No. 10, 2010, pp. S518-S522. doi:10.1097/CCM.0b013e3181flcba5

[2] R. D.Truog, A. S. Brett and J. Frader, "Sounding Board:
The Problem with Futility," New England Journal of Medicine, Vol. 326, No. 23, 1992, pp. 1560-1564. doi:10.1056/NEJM199206043262310

[3] D. J. Wilkinson and J. Savulescu, "Knowing When to Stop: Futility in the ICU," Current Opinion in Anesthesiology, Vol. 24, No. 2, 2011, pp. 160-165. doi:10.1097/ACO.0b013e328343c5af

[4] J. P. Burns and R. D. Truog, "Futility: A Concept in Evolution," Chest, Vol. 132, No. 6, 2007, pp. 1987-1993. doi:10.1378/chest.07-1441

[5] B. A. Brody and A. Halevy, "Is Futility a Futile Concept?" Journal of Medicine and Philosophy, Vol. 20, No. 2, 1995, pp. 123-144. doi:10.1093/jmp/20.2.123

[6] American Society of Anesthesiologists Committee on Ethics, "Syllabus on Ethics," 1999.

[7] L. J. Schneiderman, N. S. Jecker and A. R. Jonsen, "Medical Futility: Its Meaning and Ethical Implications," Annals of Internal Medicine, Vol. 112, No. 12, 1990, pp. 949-954. doi:10.7326/0003-4819-112-12-949

[8] J. Corbin and A. Strauss, "Basics of Qualitative Research," 3rd Edition, Los Angeles, Sage, 2008.

[9] B. Glaser and A. Strauss, "The Discovery of Grounded Theory," Chicago, Aldine, 1967.

[10] J. Luce, "A History of Resolving Conflicts over End-ofLife Care in Intensive Care Units in the United States," Critical Care Medicine, Vol. 38, No. 8, 2010, pp. 16231629. doi:10.1097/CCM.0b013e3181e71530

[11] S. Frick, D. E. Uehlinger and R. M. Zuercher Zenklusen, "Medical Futility: Predicting Outcome of Intensive Care Unit Patients by Nurses and Doctors: A Prospective Comparative Study," Critical Care Medicine, Vol. 31, No. 2, 2003, pp. 456-461. doi:10.1097/01.CCM.0000049945.69373.7C

[12] J. Cassell, "Life and Death in Intensive Care," Temple University Press, Philadelphia, 2005.

[13] M. Schwarze, C. Bradley and K. Brasel, "Surgical 'BuyIn': The Contractual Relationship between Surgeons and Patients That Influences Decisions Regarding Life-Supporting Therapy," Critical Care Medicine, Vol. 38, No. 3, 2010, pp. 843-848. doi:10.1097/CCM.0b013e3181cc466b

[14] R. Dresser, "Malignant: Medical Ethicists Confront Cancer," Oxford University Press, New York, 2012.

[15] J. Dimsdale, "Psychological Stress and Cardiovascular Disease," Journal of the American College of Cardiology, Vol. 51, No. 13, 2008, pp. 1237-1246. doi:10.1016/j.jacc.2007.12.024

[16] F. Iboro, "Perceived Psycho-Emotional Influence of Aesthetics, Affluence and Environmental Sophistication on Employees' Theft Behaviours in the Workplace," IFE Psychologia, Vol. 19, No. 1, 2011. http://www.readperiodicals.com/201103/2288643401.html 